\title{
Selective Attention Modulates Neural Substrates of Repetition Priming and "Implicit" Visual Memory: Suppressions and Enhancements Revealed by fMRI
}

\author{
Patrik Vuilleumier ${ }^{1,2,4}$, Sophie Schwartz ${ }^{1}$, Stéphanie Duhoux ${ }^{1}$, \\ Raymond J. Dolan ${ }^{3}$, and Jon Driver ${ }^{3,4}$
}

\begin{abstract}
Attention can enhance processing for relevant information and suppress this for ignored stimuli. However, some residual processing may still arise without attention. Here we presented overlapping outline objects at study, with subjects attending to those in one color but not the other. Attended objects were subsequently recognized on a surprise memory test, whereas there was complete amnesia for ignored items on such direct explicit testing; yet reliable behavioral priming effects were found on indirect testing. Event-related fMRI examined neural responses to previously attended or ignored objects, now shown alone in the same or mirror-reversed orientation as before, intermixed with new items. Repetition-related decreases in fMRI responses for objects previously attended and repeated in the same orientation were found in the right posterior fusiform, lateral occipital, and left inferior frontal cortex. More anterior fusiform regions also showed some repetition decreases for ignored
\end{abstract}

\section{INTRODUCTION}

Selective attention influences our perception and memory of sensory events, with enhanced processing of relevant information but reduced processing of ignored stimuli (Mack \& Rock, 1998). Functional imaging studies show that activations in the visual cortex can be markedly decreased for visual stimuli at unattended locations, relative to the same stimuli when attended (Kanwisher \& Wojciulik, 2000; Kastner \& Ungerleider, 2000). Attention can influence selective perceptual processing even for overlapping stimuli at the same location (O'Craven, Downing, \& Kanwisher, 1999; Rees, Russell, Frith, \& Driver, 1999). Such modulation may occur at many stages along the visual pathways, including the primary cortex, but is typically more pronounced at higher levels (Driver \& Frackowiak, 2001; Kastner \& Ungerleider, 2000).

\footnotetext{
${ }^{1}$ University Medical Center, Geneva, Switzerland, ${ }^{2}$ University of Geneva, Switzerland, ${ }^{3}$ Institute of Neurology, London, ${ }^{4}$ University College London
}

objects, irrespective of orientation. View-specific repetition decreases were found in the striate cortex, particularly for previously attended items. In addition, previously ignored objects produced some fMRI response increases in the bilateral lingual gyri, relative to new objects. Selective attention at exposure can thus produce several distinct long-term effects on processing of stimuli repeated later, with neural response suppression stronger for previously attended objects, and some response enhancement for previously ignored objects, with these effects arising in different brain areas. Although repetition decreases may relate to positive priming phenomena, the repetition increases for ignored objects shown here for the first time might relate to processes that can produce "negative priming" in some behavioral studies. These results reveal quantitative and qualitative differences between neural substrates of long-term repetition effects for attended versus unattended objects.

However, behavioral studies in healthy subjects and in brain-damaged patients suggest that residual visual processing may still take place without attention, as shown by "implicit" effects in indirect tests. Whereas inattention to visual stimuli at the encoding phase can abolish later recognition on direct explicit tests (Rock \& Guttman, 1981), inattention may not eliminate later effects revealed by indirect tests, such as repetition priming, word-stem completion, or degraded picture identification (Mulligan, 1998; Merikle \& Daneman, 1996; Szymanski \& MacLeod, 1996; Parkin, Reid, \& Russo, 1990; although see also Crabb \& Dark, 1999; Bentin, Moscovitch, \& Nirhod, 1998; MacDonald \& MacLeod, 1998). Analogously, neglect patients with parietal damage and spatial attention deficits may show later priming effects on indirect memory measures for objects initially presented on the affected side even when these were not consciously reported at exposure, nor explicitly remembered later (Vuilleumier, Henson, Driver, \& Dolan, 2002; Vuilleumier, Schwartz, Clarke, Husain, \& Driver, 2001). Such findings suggest that although attention modulates neural responses, some degree of pro- 
cessing can still take place for unattended visual objects, sufficient to form some traces in the perceptual system that can produce later priming effects on indirect measures, despite the absence of explicit memories mediated by the hippocampus and other structures outside the visual cortex (e.g., Tulving \& Schacter, 1990). However, other behavioral studies suggest that a weaker activation of perceptual representations for ignored relative to attended objects may reduce subsequent priming even in indirect tests, in addition to suppressed memory in direct tests (Bentin et al., 1998), or that there are qualitative differences between priming effects obtained from attended versus ignored objects (Stankiewicz, Hummel, \& Cooper, 1998; Mulligan, 1997; Tipper, 1985). For instance, the nature of object representations activated with or without attention might differ in the extent to which these may generalize across image transformations such as mirror-reflection (e.g., Vuilleumier, Husain, Schwartz, \& Driver, in preparation; Stankiewicz et al., 1998; Biederman \& Cooper, 1991). It has been proposed that without selective attention, visual processing of ignored stimuli might be restricted to early perceptual stages in the visual system where objects are coded in a view-specific rather than view-independent manner (Vuilleumier, Henson, et al., 2002; Grill-Spector et al., 1999). However, some studies have shown that even semantic priming effects may still occur for unattended visual stimuli (Merikle, Smilek, \& Eastwood, 2001; Berti et al., 1992), indicating a relatively high level of residual processing.

Several behavioral studies have noted that although "positive priming" effects (i.e., facilitation during repetition) are typically observed from attended items, previously ignored items can sometimes lead to "negative priming" when subsequently repeated as an attended target (e.g., Tipper \& Driver, 1988; Tipper, 1985). The mechanisms of negative priming remain controversial, as its behavioral effects may depend on the test conditions (Moore, 1994), and as potentially opposing influences can be generated from the trace of an ignored object (Tipper, 2001). One limitation of purely behavioral studies is that only one outcome is usually possible (be this positive, negative, or no priming), whereas in the brain several distinct influences from ignored objects might operate simultaneously. Nevertheless, negative priming effects suggest qualitative as well as quantitative differences between priming from attended and ignored objects.

Here we used fMRI to examine repetition-related effects arising from visual objects that were either attended or ignored at initial exposure; and to identify the neural sites involved in differential long-term priming effects as a function of prior attention. We used a selective attention paradigm with overlapping objects at exposure, similar to behavioral experiments by Tipper (1985) and by Rock and Gutman (1981). At the later test phase, we presented a single object on each trial, so that we could unambiguously measure the neural responses to specific visual items. This use of "simplex probes" at test may not provide a reliable behavioral measure for any negative priming on the repetition trials (see Moore, 1994; Tipper \& Cranston, 1985), but our main interest concerned the different neural traces established by objects at exposure as a function of attention, and their long-term consequence on fMRI responses when the same items were repeated several minutes later and now all equally attended.

Neuroimaging studies have shown that repeated visual stimuli typically produce reduced fMRI responses relative to new stimuli (henceforth, "repetition suppression"), selectively arising in brain areas that code for the repeated stimulus properties (e.g., Henson, 2003; Vuilleumier, Henson, et al., 2002; Grill-Spector \& Malach, 2001; Koutstaal et al., 2001; Henson, Shallice, \& Dolan, 2000; van Turennout, Ellmore, \& Martin, 2000; Buckner et al., 1998). However, this was usually studied under conditions where the stimuli were always fully attended, at both study and test. Only a few recent studies examined how attention or task-related factors may influence repetition effects in fMRI (Eger, Henson, Driver, \& Dolan, 2004; Murray \& Wojciulik, 2004; Bentley, Vuilleumier, Thiel, Driver, \& Dolan, 2003), but all used immediate or very short-term repetition paradigms, unlike the relatively "long-term" repetition used here, where different items intervened between initial and repeated exposure, in a situation that is more relevant to the study of implicit memory (but see van Turennout et al., 2000, for priming with even longer repetition delays). Moreover, single-cell recordings in the monkey have also shown "repetition suppression" in IT neurons when their preferred visual stimulus was repeated, even after long delays (Desimone, 1996; Brown, Wilson, \& Riches, 1987) and when the stimulus was task-irrelevant (Miller, Gochin, \& Gross, 1991). Thus, by using a delayed repetition priming paradigm during fMRI, our goals were to determine: whether durable traces can be formed in the visual system for objects that were ignored at encoding; whether the neural substrates for such traces may differ qualitatively as well as quantitatively from those for attended objects; which processing stages and brain areas might be involved; and how attention might affect distinct levels of representation for objects repeated with the same versus mirror orientation (see Murray \& Wojciulik, 2004; Stankiewicz et al., 1998).

We conducted both behavioral and fMRI experiments in 40 healthy participants. In all cases, during an initial encoding phase, subjects were shown a rapid serial visual presentation (RSVP) of pairs of overlapped objects, each drawn in one of two possible colors (Figure 1). The task was to attend to stimuli with a prespecified color, and to ignore the other color (cf. Tipper, 1985; Rock \& Gutman, 1981). Such RSVP paradigm is known to induce "inattentional blindness" for ignored items on direct 
Figure 1. Illustration of stimuli at encoding and test phases during behavioral tests (Experiments 1a and 1b) and during fMRI at test (Experiment 2). (A) At study, subjects saw a rapid visual stream of displays each containing two overlapped shapes, one drawn in cyan, the other drawn in magenta (250 msec duration, with 250-msec blank intervals). These colors were isoluminant and yielded equal performance when task-relevant.

Participants had to monitor only those stimuli within a given prespecified stream of color (i.e., magenta in half of participants, cyan in others) and detect nonsense shapes infrequently presented in the attended color stream (10\% of trials). This study phase was equivalent in all three experiments. (B) At test during Experiments 1 a and 2 , black line drawings were presented one at a time (500 msec duration), including real objects from the previously attended and previously ignored streams, randomly intermingled with new real objects (and new nonsense shapes during fMRI Experiment 2). Half of the old objects were shown with the same view at test as at study, and half were mirror-reversed. In Experiment 1a, participants judged explicitly whether each stimulus had been previously seen or not at study. During fMRI for Experiment 2, participants judged whether each stimulus was a real or nonsense object. (C) At test during Experiment 1b, fragmented versions of old or new objects were shown with progressively decreasing levels of fragmentation, until participants correctly identified each object. explicit tests (Rock \& Guttman, 1981), and can reduce on-line measures of neural responses for ignored relative to attended stimuli (Rees et al., 1999; see also O'Craven et al., 1999). During the critical subsequent test phase, our participants were presented with old objects from either the previously attended or ignored stream, or with new objects, all presented singly. Our behavioral experiments examined memory performance on direct explicit testing and on more indirect ("implicit") testing. Our fMRI experiment tested for any repetition effects on neural responses evoked by old compared with new items. Further, by presenting old objects with either the same or a mirror orientation, we could examine whether attention differentially affected object representations formed at view-dependent versus view-independent stages of the visual system.

Our two behavioral studies confirmed that our RSVP paradigm induced full amnesia for the previously unattended objects on later explicit testing, but still produced some delayed priming effects from unattended objects on more indirect ("implicit") measures. However, the most critical new data come from our fMRI study. To anticipate, we found both quantitative and qualitative differences in priming-related effects for attended versus ignored objects, arising within different brain areas at multiple stages of processing. Although repeating previously attended objects produced repetition-suppression effects for several brain regions, repeating a previously ignored object also produced repetition enbancements of fMRI responses in some other areas.

\section{RESULTS}

\section{Behavioral Performance in the Study Phase of Exposure to Superimposed Objects}

The two behavioral experiments (Experiments 1a and 1b) and the fMRI experiment (Experiment 2) were conducted in three different groups of participants (Experiments 1a and 1b: $n=15$ each; Experiment 2: $n=10)$. The initial study phase was identical for all three of our experiments (Figure 1). Participants saw an RSVP stream with two overlapped shapes on each trial (250 msec duration), each drawn in a different color (magenta or cyan), while they selectively attended to stimuli in a prespecified color only (counterbalanced across subjects) and reported infrequent nonsense shape in this attended stream.

Overall, the 40 participants made correct responses on $97.4 \%$ of RSVP trials, accurately detecting $83.2 \%$ of "nonsense" targets in the relevant stream, and false alarming on only $0.9 \%$ of the nontarget trials (including nonsense shapes in the irrelevant stream). There was no difference in performance between the three experiments in the study phase. These behavioral results confirm that our participants reliably focused attention on stimuli appearing in the relevant color stream. 


\section{Experiment 1a: Direct Behavioral Test of Explicit Memory}

Following the RSVP study phase, the group of participants $(n=15)$ in Experiment 1 a was given a surprise memory test, in which they were shown one object at a time (old or new; if old, then either previously attended or ignored, and either shown in original or mirror view). Participants were asked to judge explicitly whether the object had been seen during the preceding study phase with superimposed streams. Whereas recognition was relatively good for old objects from the attended stream (58\% correct hits), explicit recognition for old objects from the unattended stream was dramatically lower (8.4\%) and did not differ from the rate of false "old" responses to new items (9.6\%). There was no significant difference in recognition between original and mirrorreversed views (see Figure $2 \mathrm{~A}$ ). A $2 \times 2$ repeatedmeasure ANOVA was performed on hit rate for correct

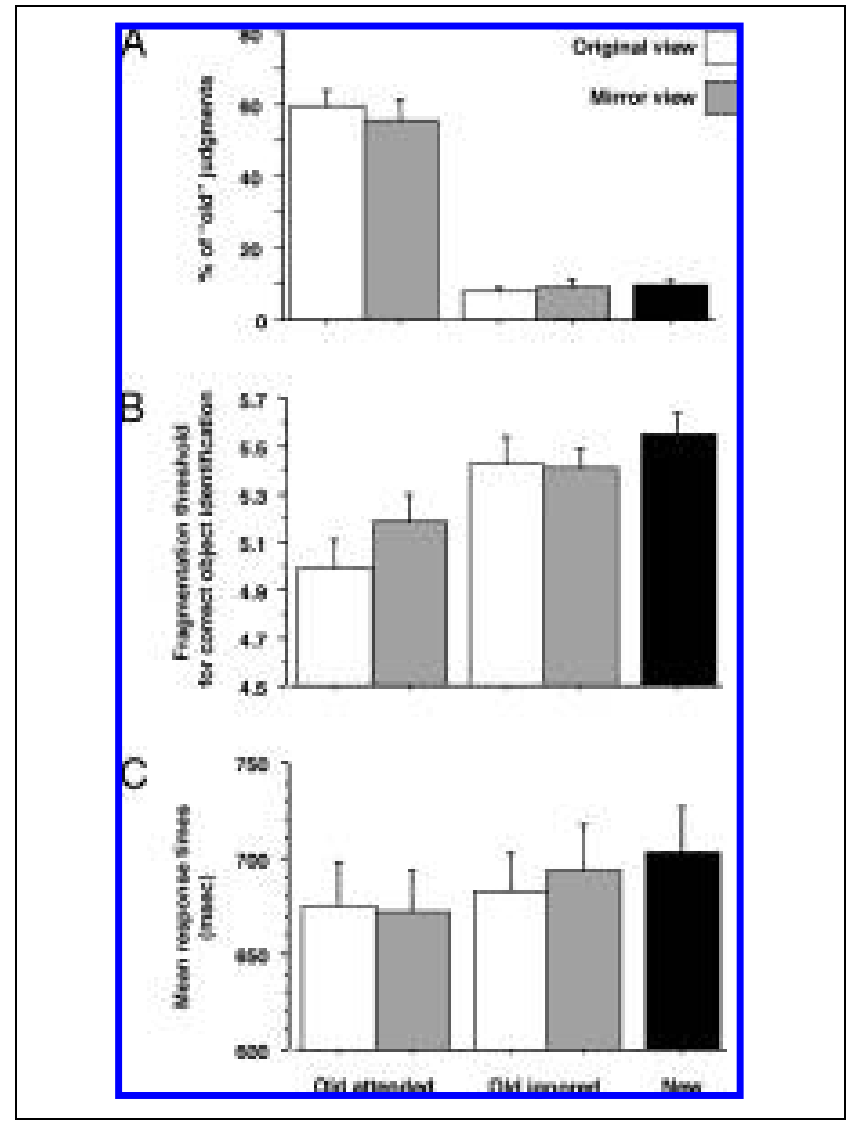

Figure 2. Behavioral results. (A) Experiment 1a. Percentage of "old" recognition judgments for each stimulus condition, showing reliable explicit memory for previously attended items, but amnesia for previously ignored items. (B) Experiment 1b. Levels of picture fragmentation at which objects were correctly identified, showing significant priming for both previously attended and previously ignored items, as compared with new items. (C) Experiment 2. Reaction times for real-object decisions during fMRI, showing faster responses for previously attended items irrespective of view, and for previously ignored items repeated with the same but not mirror view. old items, with factors of attention at study (relevant vs. irrelevant stream) and view at test (same vs. mirror in relation to study). This confirmed a significant effect of attention during the encoding phase $[F(1,14)=88.2$, $p<.0001]$, but no main effect or interaction involving view $(F<1.55, p>.24)$. These data eloquently demonstrate that selective attention to the relevant color stream during the RSVP task resulted in complete amnesia (in terms of explicit recognition) for the ignored items, even though these had been presented at the same visual location during initial exposure as the attended and later remembered items. This accords with similar findings by Tipper (1985) and by Rock and Gutman (1981).

\section{Experiment 1b: Indirect Behavioral Test Showing “Implicit" Memory for Unattended Objects}

Following the same initial RSVP study phase, a different group of participants (also $n=15$ ) was tested on an unexpected task requiring them to identify visual objects from fragmented pictures (Snodgrass \& Feenan, 1990) (Figure 1C), without requiring any explicit judgment of whether these were old or new in relation to the preceding RSVP streams. Each test stimulus was shown alone, with progressively decreasing levels of fragmentation until correct identification (see Methods). As illustrated in Figure 2B, identification thresholds were significantly higher (i.e., worse) for new than for old objects across all types of conditions [mean (SD) 5.55 (0.33) vs. 5.22 (0.37), respectively; $F(1,14)=13.3$, $p=.002]$. In addition, performance was also better for old objects from the previously attended stream than from the ignored one [mean (SD) 5.09 (0.42) vs. 5.41 $(0.36)]$. A $2 \times 2$ repeated-measure ANOVA was performed on thresholds for old items, again with the factors of attention (relevant vs. irrelevant) and view (same vs. mirror). This confirmed a strong effect of attention $[F(1,14)=50.7, p<.001]$, with no main effect of mirror views $[F(1,14)=1.92, p=.19]$ but a significant interaction $[F(1,14)=4.33, p=.05]$. This reflected better identification of same relative to mirror views for attended objects $[t(14)=2.41, p=.031]$, but no such view effect for ignored objects $[t(14)=0.26, p=.82]$. Critically, all old objects from the previously ignored RSVP stream yielded better identification thresholds relative to new object, as shown by direct pairwise comparisons of unattended old versus new items $[t(14)=3.65, p=.003$; for both same and mirror views: $t(14) \geq 2.14, p \leq .05]$.

Taken together, the behavioral results from Experiments $1 \mathrm{a}$ and $1 \mathrm{~b}$ indicate that attention not only enhanced performance on an explicit memory task (see Experiment 1a, where no explicit memory was found for previously ignored objects, and previously attended objects were accurately recognized), but also had some significant influence on the indirect task. The attended 
objects showed larger priming effects even for fragment completion, and also showed more specific traces as indicated by the benefit of same versus mirror views for old objects arising only when these were previously attended. Nevertheless, old objects from the previously ignored stream still yielded better identification thresholds than new object, thus indicating a reliable "implicit" priming effect (see Figure 2B) despite the elimination of explicit memory for items from this condition in Experiment 1a (see Figure 2A). This aspect of the results indicates that some degree of residual processing must still have arisen for ignored visual stimuli, and is consistent with many previous behavioral findings suggesting differences between direct explicit versus indirect tests of memory (e.g., Vuilleumier, Schwartz, et al., 2002; Szymanski \& MacLeod, 1996; Parkin et al., 1990; Jacoby, Woloshyn, \& Kelley, 1989).

\section{Experiment 2: Behavioral Performance during fMRI Scanning}

A third group of participants $(n=10)$ underwent wholebrain fMRI scanning following a similar RSVP study phase (which was itself performed inside the scanner in the same session, but without scanning). Whole-brain fMRI scanning was implemented during the subsequent test phase, where single old objects from the attended or ignored streams were randomly intermixed with single new objects as before, plus an additional set of nonsense shapes to permit the object-decision task (Figure 1B). All items were thus shown individually, each in turn, in unpredictable order. Participants had to make a speeded nonsense-versus-real object classification for each visual stimulus, thus ensuring equal attention to every real object during this test phase (and an equivalent behavioral response for all the previously shown objects). The trials with nonsense stimuli were not examined in the fMRI analyses.

Response accuracy did not differ between conditions (all $=98.8 \%$ correct). However, significant repetition priming effects were observed in reaction times (RTs) for the object-decision task, with faster responses to old than new objects overall [mean $(S D) 680$ (138) msec vs. 703 (153) msec, respectively; $F(1,9)=15.1, p=.003$ ]. These RT results are illustrated in Figure $2 \mathrm{C}$ for all conditions, showing a graded pattern of repetition priming across the different conditions of attention and image view. An ANOVA on RTs for old objects demonstrated a main effect of attention [with faster responses to items from the previously attended than ignored stream: mean $673 \mathrm{msec}$ vs. $688 \mathrm{msec}, F(1,9)=$ $7.41, p=.024]$. There was no significant effect of view [mean $678 \mathrm{msec}$ for original views vs. $683 \mathrm{msec}$ for mirror views, $F(1,9)=0.22]$ and no significant interaction $[F(1,9)=0.74]$. Paired $t$ tests comparing the new objects with each of the old object conditions showed significantly faster RTs for most types of repetition, that is, for original views of either the attended or ignored old items [mean RT advantage $=29$ and $21 \mathrm{msec} ; t(9)=$ 2.84 and $2.21, p=.02$ and .05 , respectively], and for mirror views of the old previously attended items [mean $\mathrm{RT}$ advantage $=31 \mathrm{msec} ; t(9)=3.72, p=.005]$. However, for mirror views of previously ignored old items, the trend was not significant [mean RT advantage = 10 msec; $t(9)=1.30, p=.22$; see Figure 2]. These data again confirm consistent priming effects for repeated objects (cf. Experiment 1b above), stronger for previously attended than ignored items, but with some effects still evident from ignored objects (here for repetition in same view on the object-decision task). This particular behavioral pattern is consistent with a previous behavioral study using RT measures for object priming across view changes (Stankiewicz et al., 1998).

\section{Event-related fMRI Results in Experiment 2}

Having established behaviorally that the present paradigm effectively manipulates attention during exposure, eliminating subsequent explicit memory for the ignored objects, but nonetheless still allowing some preserved priming from them (on two different indirect behavioral measures, see above), we now turned to the main focus of our study, namely, identifying neural responses that show common or distinct repetition effects for previously ignored versus attended stimuli, and any dependence of these effects on repetition in same or mirror view.

\section{Main and Simple Effects of Stimulus Repetition for Attended Objects}

To determine brain areas showing decreased activation for repetitions of previously seen objects (as expected given previous fMRI findings of "repetition suppression"), we first compared neural responses to new objects minus old previously attended objects. This follows previous imaging studies of repetition priming effects (e.g., Vuilleumier, Henson, et al., 2002; Buckner et al., 1998), in which stimuli were always seen with full attention at both initial exposure and subsequent repetition.

We first contrasted new objects minus old objects from the attended stream by pooling over original and mirror views, in order to identify repetition effects independent of object view. This revealed robust repetition-decreases in anterior regions of the bilateral fusiform (Figure 3A), left prefrontal, and right supplementary motor area (SMA; Figure 3C), as well as in the left parieto-occipital cortex and bilateral precuneus (Table 1A). When further examining repetition effects solely for those old, previously attended objects that were repeated in the same view, relative to new objects, we found additional decreases in posterior regions of the right fusiform and bilateral lateral occipital cortex (LOC; Figure 4A and C), as well as in the left inferior and 
Figure 3. Effects of stimulus repetition on fMRI activations during the test phase of Experiment 2, overlapped on the mean anatomical brain of participants. Main effects of New $>$ Old objects from attended stream, irrespective of view change, were found in (A) the bilateral anterior fusiform regions and left intraparietal sulcus. (B) Average parameters of activity (+ one standard error) are plotted for the right anterior fusiform cluster (peak $x y z=$ $30-60-3)$ shown in (A), across all stimulus conditions. Similar repetition decreases for New $>$ Old attended objects across all views were also found in $(\mathrm{C})$ the right medial supplementary motor area (SMA). (D) Average parameters of activity ( + one standard error) from the SMA cluster (peaks $x y z=630$ 48) shown in (C) are plotted across all stimulus conditions.

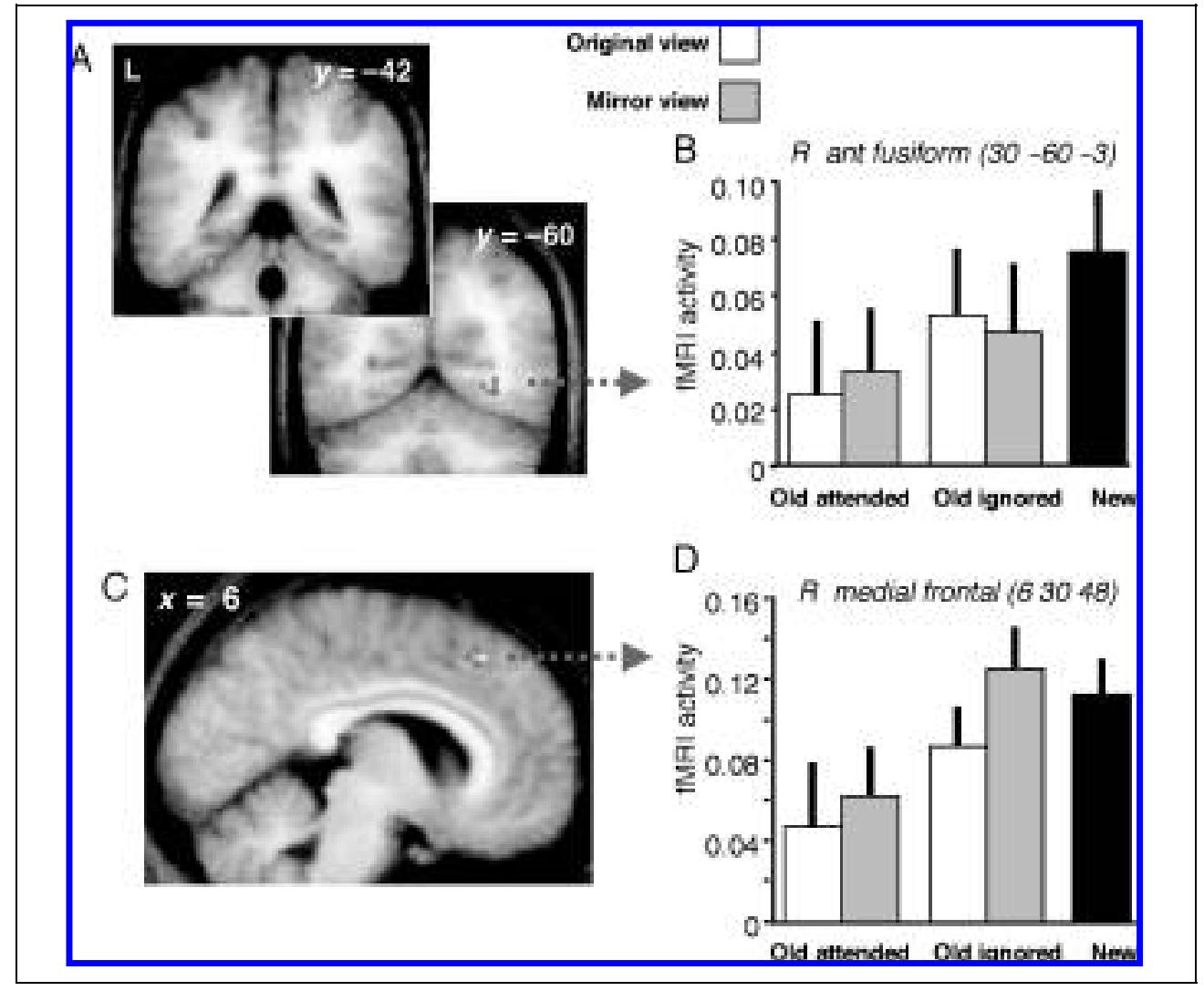

middle temporal gyri, bilateral frontal areas, and bilateral parahippocampal cortex (Table 1B). A similar pattern was apparent in the right posterior parietal cortex and right caudate.

These results already indicate that the expected repetition effects for attended objects were relatively independent of object orientation in the bilateral anterior fusiform, but more view-specific in the posterior right fusiform and lateral occipital areas. However, some viewspecific effects were also found in more anterior temporal and frontal regions for attended objects. These effects of attention and image view, and their interactions, were further examined by more detailed tests below.

\section{Influence of Selective Attention on Repetition Effects}

We next identified brain regions where repetitionrelated decreases were greater for objects previously attended at study rather than ignored. We first compared responses to old items from the previously ignored stream minus those from the attended stream, irrespective of view. This revealed activations in the anterior and posterior right fusiform cortex, as well as in the left LOC (Figure 4A and C) and bilateral lingual gyri (Figure 5). In addition, greater repetition decreases for previously attended than ignored objects were also found in the bilateral prefrontal areas and the SMA (Table 2A). Figures 3(B,D) and 4(B,D) plot activation for several regions of the visual cortex showing different repetition effects for attended and ignored objects. It can be seen that different regions showed different patterns of responses across the repeated conditions relative to new items.

Anterior fusiform regions showed a marked reduction in activity with the repetition of old objects from the previously attended stream in comparison with new objects (as described in the previous section; see Figure 3B); but a much smaller, though still present, reduction for the repetition of old previously ignored objects [as indicated by direct pairwise comparisons with new items at anterior fusiform peaks: $t(9)=2.25, p=.025$, on the right; $t(9)=2.45, p=.013$, on the left; see Figure 3B]. Furthermore, these repetition decreases in the anterior fusiform occurred regardless of view (see also the previous section): A direct comparison between original and mirror views of old objects showed no significant differences for either attended or ignored items [all $t(9)<1$ ] . By contrast, however, the more posterior fusiform and lateral occipital regions also showed reduced activity for repetition of previously attended versus ignored items, but this was significant only for items with the same rather than mirror-reversed view (see Figure $4 \mathrm{~B}$ and $\mathrm{D}$ and the previous section). Compared with new items, mirror views of old attended objects produced no repetition suppression whatsoever in the posterior fusiform and lateral occipital peaks on either side $[t(9)<1]$. 
Table 1. Repetition Decreases: "New" > "Old" Objects from the Attended Stream

\begin{tabular}{llllll}
\hline & \multicolumn{4}{c}{} & \multicolumn{3}{c}{ Cluster } \\
Brain Area & Coordinates & $t$ & Size (No. of \\
& $x$ & $y$ & $z$ & Value & Voxels) \\
\hline
\end{tabular}

(A) Regardless of view changes

$\begin{array}{lrrrrc}\text { R anterior fusiform gyrus } & 30 & -60 & -3 & 7.28 & 14^{*} \\ & 27 & -42 & -21 & 3.44 & \\ & & & \\ \text { L anterior fusiform gyrus } & -30 & -42 & -24 & 5.01 & 12^{*} \\ \text { R precuneus } & 12 & -54 & 36 & 5.13 & \\ \text { L precuneus } & -12 & -66 & 39 & 4.45 & 13 \\ \text { R medial frontal cortex } & 6 & 30 & 48 & 5.78 & 25^{*} \\ \text { L anterior inferior } & -27 & 24 & -12 & 5.33 & 55 \\ \quad \text { frontal gyrus } & & & & & \\ \text { L supramarginal gyrus } & -57 & -57 & 33 & 4.87 & 14 \\ \text { L parieto-occipital sulcus } & -24 & -78 & 39 & 4.41 & 26\end{array}$

(B) Only for same views

\begin{tabular}{|c|c|c|c|c|c|}
\hline \multirow{2}{*}{$\begin{array}{l}\text { R sup lateral occipital } \\
\text { cortex }\end{array}$} & 45 & -81 & 12 & 6.92 & $99 *$ \\
\hline & 36 & -69 & 21 & 5.53 & \\
\hline $\begin{array}{l}\text { L sup lateral occipital } \\
\text { cortex }\end{array}$ & -33 & -90 & 6 & 5.36 & 32 \\
\hline $\begin{array}{l}\mathrm{R} \text { posterior fusiform } \\
\text { cortex }\end{array}$ & 36 & -72 & -15 & 5.68 & $39 *$ \\
\hline L medial occipital cortex & -15 & -93 & 15 & 5.24 & 26 \\
\hline L inferior temporal gyrus & -45 & -54 & -6 & 5.80 & $31^{*}$ \\
\hline L middle temporal gyrus & -57 & -36 & -9 & 4.94 & 21 \\
\hline $\begin{array}{l}\text { L posterior inferior } \\
\text { frontal gyrus }\end{array}$ & -54 & 9 & 12 & 8.09 & $69 *$ \\
\hline $\mathrm{R}$ inferior frontal gyrus & 51 & 36 & -12 & 5.29 & 10 \\
\hline $\mathrm{L}$ anterior cingulate gyrus & -9 & 0 & 33 & 5.29 & 14 \\
\hline $\mathrm{R}$ caudate nucleus & 15 & 9 & 0 & 6.93 & $16^{*}$ \\
\hline $\begin{array}{l}\text { R posterior intraparietal } \\
\text { sulcus }\end{array}$ & 24 & -72 & 45 & 5.93 & $19 *$ \\
\hline R parahippocampal gyrus & 27 & -39 & -6 & 5.69 & 18 \\
\hline parahippocampal gyrus & -30 & -27 & -24 & 4.82 & 10 \\
\hline
\end{tabular}

All peaks $p<.001$, uncorrected (random-effects analysis), except (*) $p<.05$, corrected.

Finally, besides the effects in anterior fusiform regions noted above (Table 1, Figure 3A and B), no significant repetition decreases were found in other visual areas for old objects from the ignored stream as compared with new objects. The only other brain regions showing some repetition decreases for these previously ignored objects (across all views), relative to new objects, were the right
SMA $[x=9, y=12, z=39, t(9)=5.38, p<001]$ and the right caudate nucleus $[x=18, \mathrm{y}=12, \mathrm{z}=15, t(9)=$ 4.64, $p<001$ ].

On the other hand, there was a distinctive pattern of attentional modulation of repetition effects for the lingual gyri, in the bilateral posterior visual cortex (Figure 5). Neural responses in this region were not only reduced when old previously attended objects were repeated with the same view, but were markedly increased for all other repetition conditions relative to the new objects (Figure 5B and C). Such repetitionrelated increases contrast qualitatively with the repetition-related decreases usually found for items processed with full attention (e.g., Vuilleumier, Henson, et al., 2002; Koutstaal et al., 2001; Buckner et al., 1998). This repetition-related enhancement was confirmed by a contrast performed across the whole brain comparing old objects from the ignored stream, minus new objects: This revealed selective repetition-related increases in the lingual gyri in both hemispheres, extending to the LOC on the right side (Table 2C, Figure 5). No other regions across the brain showed such repetition increases. Furthermore, no increase was observed in visual areas when performing a similar contrast for old previously attended objects minus new objects.

Taken together, these results indicate that selective attention to particular visual stimuli during encoding does not only modulate the magnitude of repetition decreases in the visual cortex during the subsequent test phase (as in fusiform areas), but can also induce some region-specific repetition enbancement (i.e., in lingual areas), a qualitatively different pattern of response. In addition, the right (but not left) lingual gyrus also showed a similar repetition enhancement for old attended objects when these were repeated with a new orientation (see Figure 5C), indicating that such effect in this region may reflect traces from objects that were either previously ignored or previously perceived with a different view.

\section{Influence of Image View on Repetition Effects}

Finally, we directly tested for repetition effects influenced by changes in object orientation between initial study and test, leading to greater decreases for old objects when repeated in the same view than in a mirror view. When pooling over attentional conditions, such view-dependent effects were found in posterior visual areas, involving a left occipital area close to the primary visual cortex plus the right lingual gyrus (Table 3A, Figure 6).

However, these view-specific decreases were always more pronounced for objects that had been attended at study (reminiscent of the behavioral pattern of priming in Experiment 1b). Thus, when examining repetition effects solely for old previously attended objects that were now repeated in the same view, as compared with 
Figure 4. Effects of stimulus repetition on fMRI activations during the test phase of Experiment 2, overlapped on the mean anatomical brain scan of participants, for New $>$ Old attended objects in the same view only. This comparison showed additional repetition decreases as compared with the effects shown in Figure 3, involving $(\mathrm{A}, \mathrm{B})$ the posterior right fusiform cortex, as well as $(\mathrm{C}, \mathrm{D})$ the lateral occipital cortex bilaterally, and (C,E,F) the left inferior frontal cortex. Average parameters of activity $(+$ one standard error) are plotted for (B) the posterior right fusiform cluster (peak $x y z=36-72-15)$ shown in (A); (D) the right lateral occipital cluster $($ peak $x y z=$ $45-81$ 12) shown in (C); and (F) the left inferior frontal cluster (peaks $x y z=-54912$ ) shown in (E).

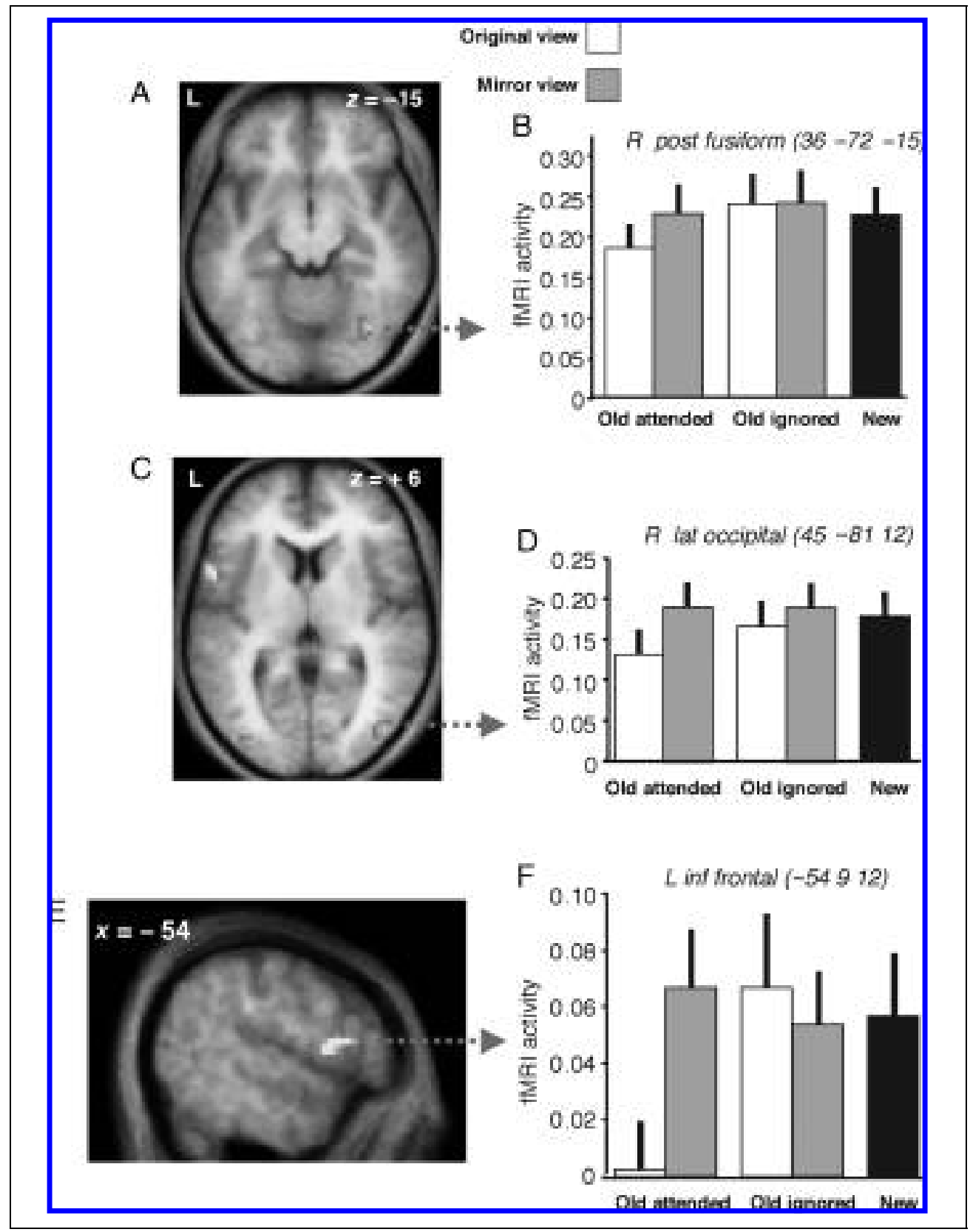

new objects, further decreases were found in bilateral extrastriate areas, as well as in the left inferior frontal gyrus, left parahippocampal cortex, and left middle temporal gyrus (Table 3B).

Same-view versus mirror-view repetition decreases were not significant for objects previously presented in the ignored stream [except for a weak trend in the left occipital cortex and right lingual gyrus, $t(9)=2.12$, $p=.03]$.

This dependency of view-specific effects on attention was formally confirmed by a direct test of the interaction between view and repetition across the whole brain [(same $<$ mirror attended) vs. (same $<$ mirror ignored)], allowing us to identify any region showing greater repetition decreases for same versus mirror views of attended objects, but not for same versus mirror views of ignored objects. This interaction confirmed view-specific decreases for attended objects in several areas including the LOC on both sides (42 $-7224, z=4.10 ;-42-7527, z=3.08$ ), bilateral lingual gyri $(12-87-12, z=3.04 ;-18-81-3, z=3.67)$, right fusiform cortex $(27-81-27, z=2.81 ; 18-45$ $-21, z=3.11)$, left middle temporal gyrus $(-57-48$ $-6 ; z=3.09$ ), and bilateral inferior frontal regions (24 $51-3, z=3.79 ;-51627, z=3.73 ; p<001)$. All these peaks overlapped with activations revealed by the simple main effects of repetition and of view reported above. As expected, the opposite interaction (any 


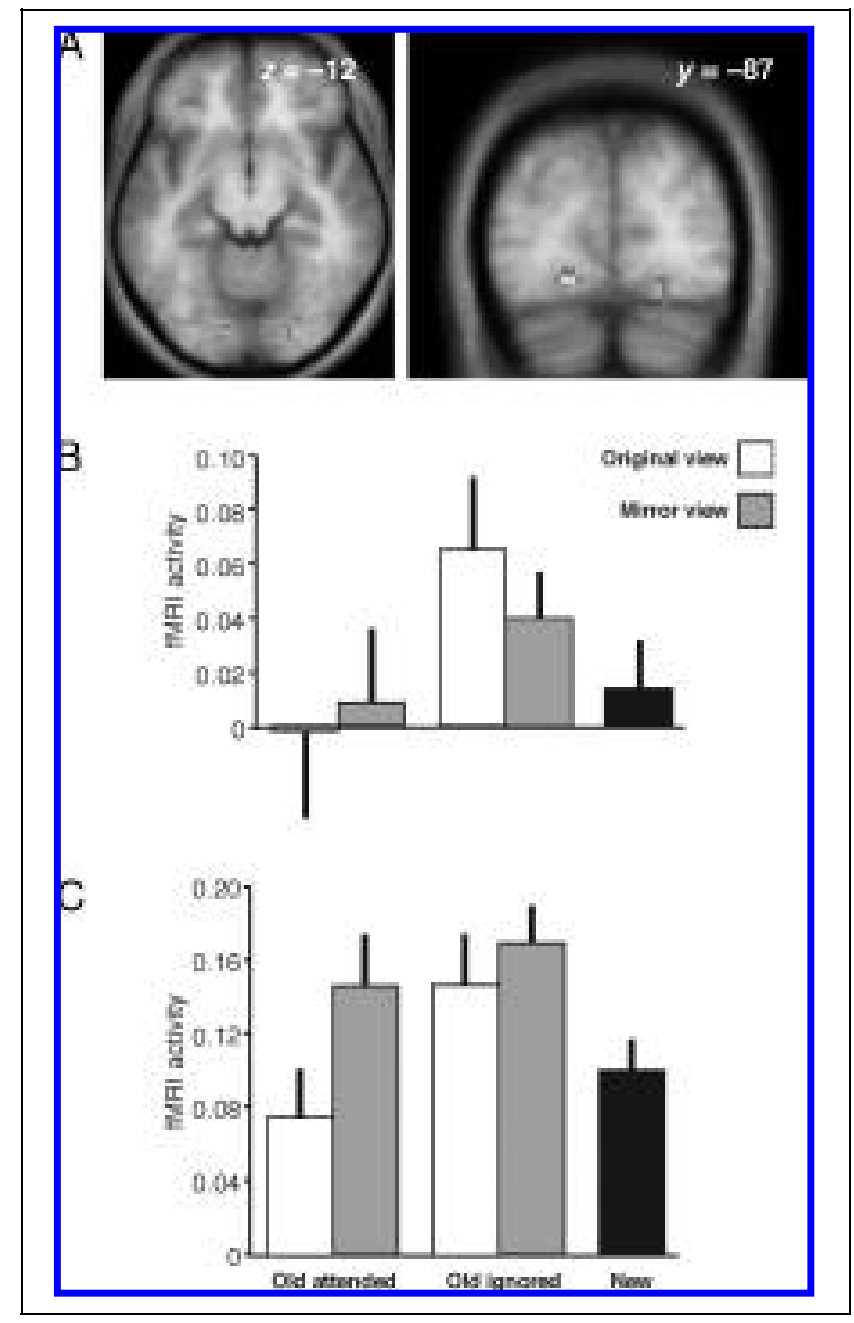

Figure 5. Activations in the lingual cortex, overlapped on the mean anatomical brain scan of participants. (A) Bilateral lingual areas showed a distinct pattern of repetition enhancement for Old ignored $>$ New objects on both sides. Average parameters of activity ( + one standard error) from activated clusters in (B) left lingual (peak $x y z=-18-87$ -12 ) and (C) right lingual (peak $x y z=18-87-15$ ).

greater decreases for same vs. mirror views with ignored but not attended objects) showed no significant activation.

\section{DISCUSSION}

Our study demonstrates that selective attention can influence the long-term traces of objects in the visual system, but also that even ignored objects can produce durable effects, both behavioral and neural, which, however, differ both qualitatively and quantitatively from those of previously attended objects. Selective attention to one or the other stream of superimposed objects at exposure had profound and long-lasting effects on explicit memory, with good recognition for attended objects but complete "amnesia" for the previously ignored objects (Experiment 1a), even though these had appeared overlapped with the attended objects. This lack of explicit memory following inattention confirms the work of Rock and Gutman (1981), who used nonsense shapes rather than outlines of real objects as here (see also Rees et al., 1999). But importantly, more indirect behavioral measures revealed residual ("implicit") effects even for the previously ignored objects, with significant perceptual priming in fragment identification (Experiment 1b) and faster RTs for object-decision during fMRI (Experiment 2) in comparison with new objects. These behavioral results confirm for our paradigm that attentional manipulations at study can exert contrasting effects on direct versus indirect measures of memory (Vuilleumier, Henson, et al., 2002; Mulligan, 1998; Merikle \& Daneman, 1996; Szymanski \& MacLeod, 1996).

Our manipulation of object view (repeated with same orientation as at exposure, or mirror-reversed) allowed us to identify distinct forms of visual object representation that were differentially activated with and without attention at encoding, and differentially involved in

Table 2. Effects of Attention on Subsequent Repetition Decreases

\begin{tabular}{llllll}
\hline & & & & & Cluster \\
Brain Area & Coordinates & $t$ & Size (No. \\
& $x$ & $y$ & $z$ & Value & of Voxels) \\
\hline
\end{tabular}

(A) All attended < ignored "old" objects

$\begin{array}{llllll}R & \text { posterior fusiform gyrus } & 27 & -75 & -15 & 5.26\end{array}$ 65*

$\begin{array}{lllll}\mathrm{R} \text { anterior fusiform gyrus } \quad 39 & -63 & -15 & 3.72\end{array}$

$\mathrm{R}$ lingual gyrus

$\begin{array}{lllll}21 & -84 & -9 & 4.12 & 10\end{array}$

L lingual gyrus

$\begin{array}{lllll}-15 & -87 & -12 & 3.88 & 10\end{array}$

L sup lateral occipital $\begin{array}{lllll}-21 & -93 & 24 & 4.16 & 16\end{array}$ cortex

L posterior inferior frontal gyrus

$\mathrm{R}$ anterior middle frontal gyrus

$\mathrm{R}$ rostral cingulate gyrus

$\mathrm{R}$ medial frontal cortex

$\begin{array}{llll}-51 & 15 & 3 & 4.98\end{array}$

$\begin{array}{llll}42 & 48 & 18 & 5.19\end{array}$

(B) Attended "old" > new objects

n.s.

(C) Ignored "old" > new objects

\begin{tabular}{lrrrrr} 
L lingual gyrus & -18 & -87 & -12 & 7.28 & $18^{*}$ \\
R lingual gyrus & 18 & -87 & -15 & 4.93 & 24 \\
R occipital cortex & 21 & -87 & 18 & 4.07 & 6 \\
\hline
\end{tabular}

All peaks $p<.001$, uncorrected (random-effects analysis), except $(*)$ $p<.05$, corrected. 
Table 3. Effects of Mirror Inversion on Subsequent Repetition Decreases

\begin{tabular}{llllll}
\hline & \multicolumn{4}{c}{ Cluster } \\
Brain Area & $x$ & $y$ & $z$ & Value & of Voxels) \\
\hline
\end{tabular}

(A) Same < mirror views, regardless of attention

$\begin{array}{lrrrrr}\text { R lingual gyrus } & 15 & -84 & -18 & 4.88 & 18 \\ \text { L medial occipital gyrus } & -9 & -102 & 0 & 4.37 & 19\end{array}$

(B) Same < mirror views, only for attended objects

\begin{tabular}{lrrrrc}
$\begin{array}{l}\text { L sup lateral occipital } \\
\text { cortex }\end{array}$ & -24 & -90 & 18 & 8.43 & $108 *$ \\
$\begin{array}{l}\text { L inferior lateral occipital } \\
\quad\end{array}$ & -33 & -90 & 3 & 6.95 & $68 *$ \\
$\quad \begin{array}{l}\text { cortex } \\
\text { R sup lateral occipital }\end{array} \quad 39$ & -78 & 21 & 5.74 & 28 \\
$\quad$ cortex \\
$\begin{array}{l}\text { R inferior lateral occipital } \\
\text { cortex }\end{array}$ & 42 & -75 & 3 & 4.72 & 28 \\
$\begin{array}{l}\text { R lingual gyrus } \\
\text { L middle temporal gyrus }\end{array}$ & -45 & -51 & -9 & 6.64 & 58 \\
L parahippocampal gyrus & -33 & -24 & -27 & 4.57 & 14 \\
L inferior frontal gyrus & -54 & 9 & 9 & 4.41 & 11 \\
\hline
\end{tabular}

All peaks $p<.001$, uncorrected (random-effects analysis), except $(*)$ $p<.05$, corrected.

subsequent repetition effects (Stankiewicz et al., 1998; Biederman \& Cooper, 1991). In our behavioral data, explicit recognition on the direct memory test was unaffected by view, implying reliance on a relatively abstract code; whereas the two indirect measures (fragment identification in Experiment $1 \mathrm{~b}$ and object decision time in Experiment 2) showed view-specific influences, with some of these effects depending on prior attention. These findings suggest that multiple representations of the exposed object (i.e., some view-specific, some generalizing across mirror reflections) may have arisen, with subsequent effects on behavioral priming depending both on the task used at test and on selective attention at initial exposure.

By using fMRI, we identified for the first time several distinct neural consequences of attention on relatively long-term object repetition effects related to implicit memory (see Eger, Henson, et al., 2004; Murray \& Wojciulik, 2004; Bentley et al., 2003) for recent studies of attentional effects in different paradigms using much shorter or immediate repetition). Here we used superimposed objects in an RSVP task at exposure, analogous to the behavioral work of Tipper (1985) and Rock and Gutman (1981). We found not only that selective attention modulated subsequent repetition effects in several brain regions; but also that even ignored objects could produce durable effects, with both quantitative and qualitative differences relative to attended objects.

Visual areas in the fusiform and LOC (plus left inferior frontal areas) showed repetition effects only for previously attended stimuli, not for previously ignored. Several of these areas showed a different sensitivity to repetition of objects with the original or mirror views depending on prior attention to the stimulus. In addition, whereas several areas showed decreased activation for old compared to new objects (i.e., repetition suppression), similar to previous studies of repetition priming using fully attended stimuli (e.g., Vuilleumier, Henson, et al., 2002; Koutstaal et al., 2001; Buckner et al., 1998), we found some areas showing increased activation for old compared with new objects (i.e., repetition enhancement). Such repetition-related increases arose selectively in the bilateral lingual gyrus, extending to the right LOC. These data demonstrate that attention at initial exposure can produce durable consequences for neural responses to visual objects, at multiple levels of processing and in distinct ways (with "repetition suppression" only for previously attended objects in some areas, but "repetition enhancement" for ignored objects in others).

Across the whole visual system, only bilateral anterior fusiform areas exhibited repetition decreases for both attended and ignored objects, although these were much stronger for attended (Figure 3A). These anterior fusiform regions were not modulated by object orientation (original or mirror view), irrespective of attention, indicating that they may hold relatively abstract object representations. This adds to previous suggestions that the anterior fusiform may code for view-invariant structural descriptions (Eger, Schyns, \& Kleinschmidt, 2004; Vuilleumier, Henson, et al., 2002) and/or semantic representations of familiar objects (Simons, Koutstaal, Prince, Wagner, \& Schacter, 2003; Koutstaal et al., 2001); but it further shows that these representations

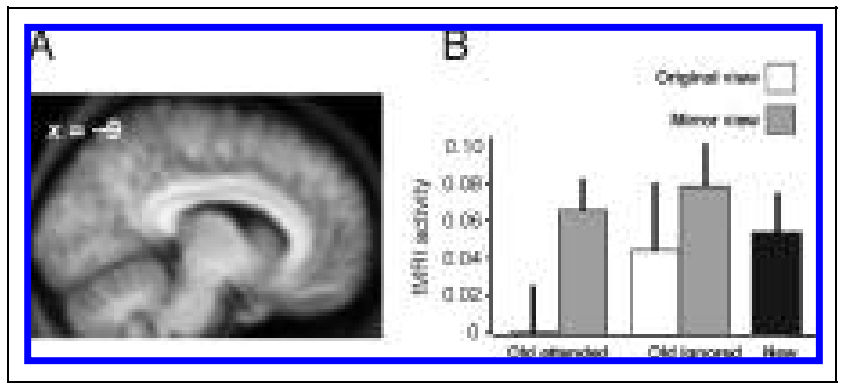

Figure 6. Repetition effects for Mirror > Same views of old objects, irrespective of previous attention condition, overlapped on the mean anatomical brain scan of participants. (A) View-specific repetition decreases were found in the left medial occipital cortex (peak $x y z=$ $-9-1020$ ). (B) Average parameters of activity ( + one standard error) from this occipital cluster show that view-specific effects predominated for attended relative to ignored old objects. 
can be activated and generalized across mirror views even for ignored objects. These residual repetition effects in high-level extrastriate areas for ignored objects provide a plausible neural substrate for earlier behavioral findings that abstract (even semantic) priming can arise without attention (Merikle et al., 2001; Berti et al., 1992; Tipper \& Driver, 1988). Note also that repetition effects in these areas were clearly stronger for attended than for ignored objects, consistent with the stronger behavioral view-independent priming found in the object-decision task for attended items (Experiment 2), and the stronger view-independent traces during the explicit memory test (Experiment 1a).

Unlike these view-independent effects, we found that more posterior regions in the right fusiform and bilateral LOC showed repetition decreases only when visual objects were previously attended and repeated with the same view. This accords with previous studies using immediate (e.g., Kourtzi \& Kanwisher, 2000; Grill-Spector et al., 1999) or longer-term repetitions (e.g., Vuilleumier, Henson, et al., 2002; Koutstaal et al., 2001; van Turennout et al., 2000; Buckner et al., 1998) for visual stimuli that were always attended. Here we show that these viewspecific repetition effects in the posterior fusiform and LOC are entirely eliminated when objects were ignored during encoding or when objects were mirror-reversed at repetition. These view-dependent repetition effects for attended objects corroborate our previous findings with depth-rotated objects (Vuilleumier, Henson, et al., 2002), suggesting that right posterior fusiform and occipital regions may hold view-based representations of visual objects. Activation of these view-specific structural representations, enhanced by attention, might underlie the perceptual advantage for objects repeated with the same rather than different view, as seen in the fragment identification task (Experiment 1b).

Conversely, we found no view-specific effect for old objects from the ignored stream, except for weak repetition decreases in early occipital cortices (see Figure 6). This fact, plus the presence of view-independent effects for ignored objects in the anterior fusiform, argues against previous proposals on the basis of theoretical or purely behavioral work (Stankiewicz et al., 1998) that unattended visual objects activate just early view-based representations, whereas attended objects would activate more abstract representations underlying priming across different views. In fact, our fMRI results showed view-specific repetition effects mainly for attended rather than ignored objects (e.g., in the posterior fusiform and LOC). Our fMRI data therefore accord with the idea that attention may enhance perceptual tuning and selectivity of neuronal populations (Spitzer, Desimone, \& Moran, 1988). Recent fMRI results (Murray \& Wojciulik, 2004) showed that responses in the LOC decreased for immediate repetitions of visual shapes presented in attended pairs, with greater orientation specificity for the attended pairs than for the unattended pairs. Simi- larly, we show here that even view-specific representations in the visual cortex can be strengthened for attended relative to ignored objects (not only the more abstract view-independent representations).

Behavioral view-specific effects for unattended objects have previously been reported for a short-term (immediate repetition) priming task (Stankiewicz et al., 1998), but not over long intervals as in our study. Any viewspecific traces for unattended objects might be shortlived and perhaps need attention for consolidation to resist temporal decay or interference due to other intervening stimuli. On the other hand, an fMRI study by Eger, Henson, et al. (2004), using a short-term paradigm similar to Stankiewicz et al., found no view-specific effects from immediate repetition for either attended or ignored objects, although in that study attended and ignored objects were presented at different locations, unlike the superimposed objects used here.

Note that our findings of view-specific repetition effects in the medial occipital cortex suggest that even early (retinotopic) visual areas may be modulated by perceptual learning during long-term repetition priming, either directly or via a feedback mechanism. Previous imaging studies did not observe significant repetition decreases in the early occipital cortex (Vuilleumier, Henson, et al., 2002; Grill-Spector et al., 1999; Buckner et al., 1998), but some short-lived and pattern-specific adaptation effects have been observed in V1 in monkeys (Muller, Metha, Krauskopf, \& Lennie, 1999). Here, repetition suppression in medial occipital areas arose for old objects repeated in the same view, but were stronger for attended than ignored objects (see Table $3 \mathrm{~A}$ and Figure 6), suggesting that behavioral view-specific priming for ignored visual stimuli (Stankiewicz et al., 1998) might partly result from short-lived traces at these early stages of visual processing.

A further important and novel finding in our fMRI data was that selective attention not only amplified subsequent repetition suppression for previously attended stimuli in several brain areas, but also produced selective repetition enhancement for previously ignored stimuli in the bilateral lingual cortex. Thus, activations in the lingual cortex were significantly higher for old ignored items than for new items. To our knowledge, this is the first demonstration of repetition producing either suppressive or enhancement effects on fMRI responses, as a function of attention. This enhancement for previously unattended items cannot be explained by unspecific changes from inattention at study to attention at test as other brain regions (e.g., fusiform cortex) showed repetition decreases for the very same items at test, and entirely new items did not produce such effects. Because repetition suppression, as seen in previous neuroimaging and neurophysiological studies, may relate to positive behavioral priming effects (Henson, 2003; Wiggs \& Martin, 1998), it would be tempting to speculate that the repetition enhancements observed here for ignored 
objects might relate to neural mechanisms that can produce negative priming in some behavioral tasks, when a previously ignored object later becomes a target, leading to slower rather than faster performance (Tipper \& Driver, 1988; Tipper, 1985). This negative priming has often been interpreted as resulting from temporary inhibition of the representation of ignored stimuli (Tipper, 2001; Fox, 1994; Neill, Lissner, \& Beck, 1990; but see Milliken \& Rock, 1997; Neill, Valdes, Terry, \& Gorfein, 1992). Negative priming may arise particularly in situations when attention must exclude distractors in favor of the target (Tipper \& Driver, 1988), when shape stimuli with outlined contours but no surface cues are overlapped (Loula, Kourtzi, \& Shiffrar, 2000), and when explicit awareness of the ignored stimulus is eliminated (Tipper, 2001); all conditions were quite similar to our RSVP study phase. Moreover, negative priming can operate even for novel shapes (DeSchepper \& Treisman, 1996), suggesting that it can involve early stages of shape processing, possibly in accord with the lingual sites showing fMRI repetition enhancement for ignored objects here.

On the one hand, it should be acknowledged that there was no clear behavioral evidence for negative priming in our experiments. On the other hand, negative priming is rarely observed behaviorally when test probes are shown alone (Moore, 1994; Tipper \& Cranston, 1985), as used here (to allow unambiguous measures for each specific item). But although overt manifestations of negative priming may depend on attentional conflicts at test, this obviously cannot change the critical effect of attention at initial exposure. Moreover, behavioral effects typically result from a balance between concurrent processes with potentially opposing positive and negative influences (Ortells, Fox, Noguera, \& Abad, 2003; Neumann \& DeSchepper, 1991), whereas such opposing influences might more easily be disentangled using fMRI if they affect distinct brain sites. It is possible that if repetition enhancement in the lingual cortex relate to negative priming effects, such effects might have become apparent behaviorally in some other task. Moreover, repetition effects in visual areas might also reflect a combination of top-down effects due to attention factors and bottom-up effects of repetition in perceptual processing (Henson, 2003; Dale et al., 2000). Further studies are needed to investigate the exact relationship between behavioral negative priming and fMRI repetition enhancement, but here we clearly demonstrate for the first time that the latter can depend on attention. To our knowledge, only one previous imaging study examined negative priming (Steel et al., 2001) but during a Stroop interference task with immediate repetitions, and showed greater frontal and parietal activations on interference trials but with no effect in the visual cortex.

More generally, we note that the pattern of behavioral effects for the different conditions in our paradigm could not be directly mapped onto the patterns of neural activity in a single area of the brain. Only the premotor cortex in the SMA exhibited a profile of activity (Figure 3C) resembling the graded pattern seen for RTs across conditions during fMRI (Figure 2C, with responses for attended $<$ ignored $<$ new items, and same $<$ mirror views in each attention condition). This may be consistent with a crucial role of this region in motor selection and execution (Amador \& Fried, 2004), and suggests that although several distinct representations of object shape are involved in visual recognition and modulated by various repetition effects, their differential contribution to any given task might be integrated only towards the output response stage, jointly influencing the premotor cortex.

In conclusion, our results show that selective attention has profound and durable consequences for behavior and neural activation, even for visual objects presented at overlapping locations. Explicit memory occurs only for attended objects, but some long-term traces can still be established for ignored objects, revealed in indirect (or "implicit") behavioral tests, and in later fMRI repetition effects. Our fMRI results showed repetition suppression in fusiform and lateral occipital areas, arising only for previously attended objects. Attention also enhanced the view-specificity of perceptual traces in these regions, with greater repetition decreases for same than mirror-views for attended (but not ignored) stimuli. Bilateral anterior fusiform showed repetition suppression for both attended and previously ignored objects, but was stronger in the former case, and regardless of view. Importantly, selective attention also induced subsequent repetition enbancement in neural responses to previously ignored objects, selectively affecting the bilateral lingual cortex, and possibly reflecting some inhibition of ignored visual shapes. Taken together, our data provide striking evidence that long-term repetition effects depend profoundly on attention at exposure, involving different view-specific and view-independent representations of objects, and several different neural sites. Future studies should further investigate such effects of attention on repetition priming across even longer delays (hours, days, etc.; see Van Turrenout et al., 2000).

\section{METHODS}

\section{Participants}

Forty right-handed healthy volunteers participated. Fifteen were included in each of the behavioral studies (Experiments 1a and 1b; 30 in total for the purely behavioral work; 12 men, age range 19-36 years, mean 26). Another 10 participants took part in the fMRI study (Experiment 2; 6 men, age range 20-36 years, mean 27). All gave informed consent in accord with the Joint Ethics Committee of the National Hospital and Institute of 
Neurology. Five additional volunteers were excluded on the basis of poor performance for the selective attention task during exposure and/or excessive movements during scanning. Participants had normal vision without color blindness.

\section{Behavioral Tasks}

Each experiment began with an identical initial study phase, followed by a subsequent, unexpected test phase after a short resting interval of $\sim 5 \mathrm{~min}$. Only this second test phase differed between the experiments. Both the study and test phases of Experiment 2 took place in the MRI scanner environment.

The study phase always consisted of RSVPs of pairs of overlapped outline shapes (Figure 1A), shown concurrently at central fixation (250 msec duration, separated from next display by a $250-\mathrm{msec}$ blanks interval), with one in magenta and one in cyan color. Each shape depicted a real object (from Snodgrass \& Vanderwart, 1980), or more rarely a "nonsense" shape in similar outline format. Participants were instructed to attend only to the stimuli drawn in one prespecified color (counterbalanced across subjects) and to report by keypress with the right index any infrequent (10\%) nonsense shapes among the real objects in this color, while ignoring all stimuli in the other color The RSVP stream included 50 different real objects in the attended color and 50 other real objects in the ignored color, each shown four times in random order within the same stream; plus 25 nonsense targets (requiring response) in the attended color and 25 nonsense distracters in the ignored color. Real objects paired with a nonsense stimulus were not used in the subsequent test phase.

The test phase consisted of one of three possible tasks allowing us to test for explicit object recognition behaviorally (Experiment 1a); for priming effects on an indirect behavioral measure, using fragmented object identification (Experiment 1b); and for repetition-related effects on behavior (RTs) and neural activity in fMRI (Experiment 2). In each experiment, the "old" real objects from the RSVP task were now shown singly, and in black rather than in colored outline, in a randomly intermingled sequence with 50 new objects (see Figure $1 \mathrm{~B}$ and $\mathrm{C}$ ). In Experiments $1 \mathrm{a}, 1 \mathrm{~b}$, and 2, half the old objects were repeated with the same orientation as during the study phase, half were shown in a mirrorreversed orientation, resulting in five critical experimental conditions at test: old items from the attended color stream, in same or mirror view; old items from the unattended color stream, in same or mirror view; and new items not shown at study. Specific items were counterbalanced between conditions across participants. Experiment 1a tested for explicit old/new recognition performance (i.e., judging whether the item had been previously shown during the RSVP task with overlapping shapes). Experiment $1 \mathrm{~b}$ assessed memory traces with an indirect test, requiring participants to identify fragmented versions of old or new objects (Snodgrass \& Feenan, 1990; Snodgrass \& Corwin, 1988), without any requirement to judge if these had been shown during study. We determined the recognition threshold for each object by presenting the test picture first in a very fragmented version, and then in progressively more completed versions until the object was correctly identified (Figure 1C), across height fragmentation levels (Snodgrass \& Feenan, 1990; Snodgrass \& Corwin, 1988). Each test item was presented until response in Experiments $1 \mathrm{a}$ and $1 \mathrm{~b}$.

During the test phase of Experiment 2 (fMRI), participants had to make an object decision (real or nonsense) for each item presented singly, by pressing one key for real objects and another key for nonsense shapes. Fifty new nonsense shapes were added to the old and new objects for the task purpose, but were not used in subsequent analyses. The object-decision task for this phase was chosen to ensure an equal cognitive processing demand and the same behavioral response for all old objects at test during fMRI. Each stimulus was shown for $500 \mathrm{msec}$, preceded by a 500-msec fixation cross. Intertrial intervals were randomly jittered between 2 and $6 \mathrm{sec}$ (with the addition of "null" events where no stimulus was shown).

Experiments 1a and 1b were performed on a PC. During Experiment 2 in the scanner, stimuli were projected by an LCD projector onto a mirror box mounted on the head coil. In all experiments, stimuli subtended $\sim 10^{\circ} \times 10^{\circ}$ of visual angle. Stimulus presentation and response recording were controlled using a custom MATLAB toolbox allowing precise synchronization with MRI acquisitions (Cogent 2000, www.vislab. ucl.ac.uk/Cogent/).

\section{MRI Data Collection}

fMRI time-series were acquired at $2 \mathrm{~T}$ using a Magnetom VISION (Siemens, Erlangen, Germany) whole-body MRI system. Multislice T2*-weighted fMRI images were obtained with a gradient echo-planar sequence using an axial slice orientation $(\mathrm{TE}=40 \mathrm{msec}$, $\mathrm{TR}=2.736 \mathrm{sec}$, $64 \times 64 \times 36$ voxels, voxel size: $3 \times 3 \times 3 \mathrm{~mm}$ ). After discarding the 7 initial scans (to allow for magnetic saturation effects), each time-series comprised $374 \mathrm{vol}-$ ume images. A structural T1-weighted sequence scan was also obtained.

\section{Analysis of fMRI Data}

Functional volumes were analyzed on a voxel-by-voxel basis across the whole brain using Statistical Parametric Mapping (SPM99, www.fil.ion.ucl.ac.uk). They were spatially realigned to the first volume, time-corrected with reference to the middle slice, spatially normalized to an EPI template conforming to the MNI space, smoothed 
with an 8-mm FWHM Gaussian kernel, and high-pass filtered at $1 / 120 \mathrm{~Hz}$.

For each subject, event-related changes in regional brain activity were estimated by a general linear model in which responses evoked by each condition of interest were modeled by a standard delta function at stimulus onset (Friston, Fletcher, et al., 1998; Friston, Holmes, et al., 1995). There were six different events types, including old attended and old unattended objects, each either in original views or mirror views, plus new objects and nonsense shapes (the latter were included for task purposes but excluded in subsequent analyses). All six conditions were entered as separate covariates in a multiple regression analysis within a single-design matrix, to estimate parameter estimates for each covariate at each brain voxel, in each individual participant. Movement parameters derived from realignment were also included as covariates of no interest. The effects of interest were then tested by linear contrasts, generating SPMs for different conditions in each individual participant. We then performed random-effect group analyses on the contrast images using one-sample $t$ tests (Friston et al., 1998). We report regions that survived $p<.05$, volume-corrected, using either the mean volume of regions showing main effects of repetition in individual subjects (Worsley et al., 1996) or 10-mm spheres centered on peaks in the lateral occipital and temporal cortex found in a previous study of object priming from our laboratory (Vuilleumier, Henson, et al., 2002). We also tabulate other peaks that survived $p<.001$, uncorrected with an extension of at least 10 contiguous voxels at $p<.005$. Additional statistical comparisons were performed on parameter estimates of activity extracted from specific voxels of interest using paired $t$ test or repeated-measure ANOVAs where indicated. Illustration of fMRI activity was plotted using parameter estimates scaled to arbitrary units.

\section{Acknowledgments}

This work was supported by grants from the Swiss National Fund to PV (632.065935) and to SS (3100-AO-102133); a Royal Society-Wolfson Research Merit Award (JD); and Wellcome Trust Programme Grants (JD, RD).

Reprint requests should be sent to P. Vuilleumier, Lab for Neurology and Imaging of Cognition, Department of Neurosciences and Physiology, Rm 7042, University Medical Center, 1 Michel Servet, 1211 Geneva, Switzerland, or via e-mail: patrik.vuilleumier@medecine.unige.ch.

The data reported in this experiment have been deposited with The fMRI Data Center archive (www.fmridc.org). The accession number is 2-2005-118C3.

\section{REFERENCES}

Amador, N., \& Fried, I. (2004). Single-neuron activity in the human supplementary motor area underlying preparation for action. Journal of Neurosurgery, 100, 250-259.
Bentin, S., Moscovitch, M., \& Nirhod, O. (1998). Levels of processing and selective attention effects on encoding in memory. Acta Psvchologica, 98, 311-341.

Bentley, P., Vuilleumier, P., Thiel, C. M., Driver, J., \& Dolan, R. J. (2003). Effects of attention and emotion on face repetition priming and their modulation by cholinergic enhancement. Journal of Neurophysiology, 90, 1171-1181.

Berti, A., Allport, A., Driver, J., Dienes, Z., Oxbury, J., \& Oxbury, S. (1992). Level of processing for stimuli in an "extinguished" visual field. Neuropsychologia, 30, $403-415$.

Biederman, I., \& Cooper, E. E. (1991). Evidence for complete translational and reflectional invariance in visual object priming. Perception, 20, 595-593.

Brown, M. W., Wilson, F. A., \& Riches, I. P. (1987). Neuronal evidence that inferomedial temporal cortex is more important than hippocampus in certain processes underlying recognition memory. Brain Research, 409, 158-162.

Buckner, R. L., Goodman, J., Burock, M., Rotte, M., Koutstaal, W., Schacter, D., Rosen, B., \& Dale, A. M. (1998). Functional-anatomic correlates of object priming in humans revealed by rapid presentation event-related fMRI. Neuron. 20, 285-296.

Crabb, B. T., \& Dark, V. J. (1999). Perceptual implicit memory requires attentional encoding. Memory \& Cognition, 27, 267-275.

DeSchepper, B., \& Treisman, A. (1996). Visual memory for novel shapes: Implicit coding without attention. Iournal of Experimental Psychologv: Learning. Memorv. and Cognition, 22, 27-47.

Dale, A. M., Liu, A. K., Fischl, B. R., Buckner, R. L., Belliveau, J. W., Lewine, J. D., \& Halgren, E. (2000). Dynamic statistical parametric mapping: Combining fMRI and MEG for high-resolution imaging of cortical activity. Neuron, 26, 55-67.

Desimone, R. (1996). Neural mechanisms for visual memory and their role in attention. Proceedings of the National Academv of Sciences. U.S.A., 93, 13494-13499.

Driver, J., \& Frackowiak, R. S. (2001). Neurobiological measures of human selective attention. Neuropsychologia. 39, 1257-1262.

Eger, E., Henson, R. N. A., Driver, J., \& Dolan, R. J. (2004). BOLD repetition decreases in object-responsive ventral visual areas depend on spatial attention. Journal of Neuropbysiology, 92, 1241-1247.

Eger, E., Schyns, P. G., \& Kleinschmidt, A. (2004). Scale invariant adaptation in fusiform face-responsive regions. Neuroimage, 22, 232-242.

Fox, E. (1994). Interference and negative priming from ignored distractors: The role of selection difficulty. Perception $\&$ Psychophysics, 56, 565-574.

Friston, K. J., Fletcher, P., Josephs, O., Holmes, A., Rugg, M. D., \& Turner, R. (1998). Event-related fMRI: Characterizing differential responses. Neuroimage, 7, 30-40.

Friston, K. J., Holmes, A. P., Worsley, K. J., Poline, J. B., Frith, C. D., \& Frackowiak, R. S. J. (1995). Statistical parametric maps in functional imaging: A general linear approach. Human Brain Mapping, 2, 189-210.

Grill-Spector, K., Kushnir, T., Edelman, S., Avidan, G., Itzchak, Y., \& Malach, R. (1999). Differential processing of objects under various viewing conditions in the human lateral occipital complex. Neuron, 24, 187-203.

Grill-Spector, K., \& Malach, R. (2001). fMR-adaptation: A tool for studying the functional properties of human cortical neurons. Acta Psychologica (Amsterdam), 107, 293-321. 
Henson, R., Shallice, T., \& Dolan, R. (2000). Neuroimaging evidence for dissociable forms of repetition priming. Science, 287, 1269-1272.

Henson, R. N. (2003). Neuroimaging studies of priming. Progress in Neurobiology, 70, 53-81.

Jacoby, L. L., Woloshyn, V., \& Kelley, C. (1989). Becoming famous without being recognized: Unconscious influences of memory produced by dividing attention. Journal of Experimental Psychology: General, 118, 115-125.

Kanwisher, N., \& Wojciulik, E. (2000). Visual attention: Insights from brain imaging. Nature Reviews: Neuroscience, 1, 91-100.

Kastner, S., \& Ungerleider, L. G. (2000). Mechanisms of visual attention in the human cortex. Annual Review of Neuroscience, 23, 315-341.

Kourtzi, Z., \& Kanwisher, N. (2000). Cortical regions involved in perceiving object shape. Journal of Neuroscience, 20, 3310-3318.

Koutstaal, W., Wagner, A. D., Rotte, M., Maril, A., Buckner, R. L., \& Schacter, D. L. (2001). Perceptual specificity in visual object priming: Functional magnetic resonance imaging evidence for a laterality difference in fusiform cortex. Neuropsychologia. 39, 184-199.

Loula, F., Kourtzi, Z., \& Shiffrar, M. (2000). Surface segmentation cues influence negative priming for novel and familiar shapes. Journal of Experimental Psvchologv: Learning Memorv and Cognition, 26, 929-944.

MacDonald, P. A., \& MacLeod, C. M. (1998). The influence of attention at encoding on direct and indirect remembering. Acta Psychologica, 98, 291-310.

Mack, A., \& Rock, I. (1998). Inattentional blindness. Cambridge: MIT Press.

Merikle, P., Smilek, D., \& Eastwood, J. D. (2001). Perception without awareness: Perspectives from cognitive psychology. Cognition, 79, 115-134.

Merikle, P. M., \& Daneman, M. (1996). Memory for unconsciously perceived events: Evidence from anesthetized patients. Consciousness and Cognition, 5, 525-541.

Miller, E. K., Gochin, P. M., \& Gross, C. G. (1991). Habituation-like decrease in the responses of neurons in inferior temporal cortex of the macaque. Visual Neuroscience, 7, 357-362

Milliken, B., \& Rock, A. (1997). Negative priming, attention, and discriminating the present from the past. Consciousness and Cognition, 6, 308-327.

Moore, C. M. (1994). Negative priming depends on probe-trial conflict: Where has all the inhibition gone? Perception \& Psychophysics, 56, 133-147.

Muller, J. R., Metha, A. B., Krauskopf, J., \& Lennie, P. (1999). Rapid adaptation in visual cortex to the structure of images. Science, 285, 1405-1408.

Mulligan, N. W. (1997). Attention and implicit memory tests: The effects of varying attentional load on conceptual priming. Memory \& Cognition, 25, 11-17.

Mulligan, N. W. (1998). The role of attention during encoding in implicit and explicit memory. Journal of Experimental Psychology: Learning. Memory. and Cognition, 24, 27-47.

Murray, S. O., \& Wojciulik, E. (2004). Attention increases neural selectivity in the human lateral occipital complex. Nature Neuroscience, 7, 70-74.

Neill, W. T., Lissner, L. S., \& Beck, J. L. (1990). Negative priming in same-different matching: Further evidence for a central locus of inhibition. Perception \& Psychophysics, 48, $398-400$.

Neill, W. T., Valdes, L. A., Terry, K. M., \& Gorfein, D. S. (1992). Persistence of negative priming: II. Evidence for episodic trace retrieval. Journal of Experimental Psvchology: Learning. Memory and Cognition, 18, 993-1000.
Neumann, E., \& DeSchepper, B. G. (1991). Costs and benefits of target activation and distractor inhibition in selective attention. Iournal of Experimental Psychologv: Learning. Memory and Cognition, 17, 1136-1145.

O'Craven, K. M., Downing, P. E., \& Kanwisher, N. (1999). fMRI evidence for objects as the units of attentional selection. Nature, 401, 584-587.

Ortells, J. J., Fox, E., Noguera, C., \& Abad, M. J. (2003). Repetition priming effects from attended vs. ignored single words in a semantic categorization task. Acta Psychologica (Amsterdam), 114, 185-210.

Parkin, A. J., Reid, T. K., \& Russo, R. (1990). On the differential nature of implicit and explicit memory. Memory $\mathcal{E}$ Cognition, 18, 507-514.

Rees, G., Russell, C., Frith, C. D., \& Driver, J. (1999). Inattentional blindness versus inattentional amnesia for fixated but ignored words. Science, 286, 2504-2507.

Rock, I., \& Guttman, D. (1981). The effect of inattention on form perception. Journal of Experimental Psvchology: Human Percebtion and Performance, 7, 275-285.

Simons, J. S., Koutstaal, W., Prince, S., Wagner, A. D., \& Schacter, D. L. (2003). Neural mechanisms of visual object priming: Evidence for perceptual and semantic distinctions in fusiform cortex. Neuroimage, 19, 613-626.

Snodgrass, J. G., \& Corwin, J. (1988). Perceptual identification thresholds for 150 fragmented pictures from the Snodgrass and Vanderwart picture set. Perceptual and Motor Skills, 67, 3-36.

Snodgrass, J. G., \& Feenan, K. (1990). Priming effects in picture fragment completion: Support for the perceptual closure hypothesis. Journal of Experimental Psychologv: General, 119, 276-296.

Snodgrass, J. G., \& Vanderwart, M. (1980). A standardized set of 260 pictures: norms for name agreement, image agreement, familiarity, and visual complexity. Journal of Experimental Psvchologv: Human Learning, 6, 174-215.

Spitzer, H., Desimone, R., \& Moran, J. (1988). Increased attention enhances both behavioral and neuronal performance. Science, 240, 338-340.

Stankiewicz, B. J., Hummel, J. E., \& Cooper, E. E. (1998). The role of attention in priming for left-right reflections of object images: Evidence for a dual representation of object shape. Journal of Experimental Psychology: Human Perception and Performance, 24, 732-744.

Steel, C., Haworth, E. J., Peters, E., Hemsley, D. R., Sharma, T., Gray, J. A., Pickering, A., Gregory, L., Simmons, A., Bullmore, E. T., \& Williams, S. C. (2001) Neuroimaging correlates of negative priming. NeuroReport. 12, 3619-3624.

Szymanski, K. F., \& MacLeod, C. M. (1996). Manipulation of attention at study affects an explicit but not an implicit test of memory. Consciousness and Cognition, 5, $165-175$.

Tipper, S. P. (1985). The negative priming effect: Inhibitory priming by ignored objects. Quarterly Journal of Experimental Psychology, 37A, 571-590.

Tipper, S. P. (2001). Does negative priming reflect inhibitory mechanisms? A review and integration of conflicting views. Quarterly Journal of Experimental Psychology, 37A, 571-590.

Tipper, S. P., \& Cranston, M. (1985). Selective attention and priming: Inhibitory and facilitatory effects of ignored primes. Quarterly Journal of Experimental Psychology: A, 37, 591-611.

Tipper, S. P., \& Driver, J. (1988). Negative priming between pictures and words in a selective attention task: Evidence for semantic processing of ignored stimuli. Memory $\varepsilon$ Cognition, 16, 64-70. 
Tulving, E., \& Schacter, D. L. (1990). Priming and human memory systems. Science, 247, 301-306.

van Turennout, M., Ellmore, T., \& Martin, A. (2000). Long-lasting cortical plasticity in the object naming system. Nature Neuroscience, 3, 1329-1334.

Vuilleumier, P., Henson, R., Driver, J., \& Dolan, R. J. (2002). Multiple levels of visual object constancy revealed by event-related fMRI of repetition priming. Nature Neuroscience, 5, 491-499.

Vuilleumier, P., Husain, M., Schwartz, S., \& Driver, J. (in preparation). Visual processing of unseen objects in simultanagnosia: View-specific traces in implicit memory.

Vuilleumier, P., Schwartz, S., Clarke, K., Husain, M., \& Driver, J. (2001). Implicit processing and learning of visual stimuli in parietal extinction and neglect. Cortex, 37 , 741-744.

Vuilleumier, P., Schwartz, S., Clarke, K., Husain, M., \& Driver, J. (2002). Testing memory for unseen visual stimuli in patients with spatial neglect and extinction. Journal of Cognitive Neuroscience, 14, 875-886.

Wiggs, C. L., \& Martin, A. (1998). Properties and mechanisms of perceptual priming. Current Opinion in Neurobiolology, 8, 227-233.

Worsley, K. J., Marrett, S., Neelin, P., Vandal, A. C., Friston, K. J., \& Evans, A. C. (1996). A unified statistical approach for determining significant signals in images of cerebral activation. Human Brain Mapping, 4, $58-73$ 